\title{
Evaluation of the Viscus injury in Abdominal Trauma
}

\author{
Nishit R Santoki ${ }^{\circledR 1}$, Pranjal Sangole ${ }^{\circledR 2}$, Gyaneshwar Rao ${ }^{3}$ \\ ${ }^{1}$ Post Graduate Student, Department of Surgery, Gujarat Adani Institute of Medical Science, Bhuj, Gujarat, India, ${ }^{2}$ Assistant Professor, Department of Surgery, Gujarat \\ Adani Institute of Medical Science, Bhuj, Gujarat, India, ${ }^{3}$ Professor and Head, Department of Surgery, Gujarat Adani Institute of Medical Science, Bhuj, Gujarat, India.
}

\section{Abstract}

Background: The diagnosis of hollow viscus injury with advanced diagnostic tools and management of trauma by conservative and surgically by laparotomy and correction of anatomy. Hence such injuries are frequently overlooked leading to increased morbidity and mortality. Thus, this study is intended to throw light upon the prompt diagnosis and management of hollow viscus injuries in trauma. Hence the aim of the present research was to study the diagnosis and management of hollow viscus injuries. Subjects and Methods: A total of 100 cases were included in the study. All the patients were above the age of 11 years and maximum age of 80 years. Most of the patients included were male with ration of 4:1. After recording of history clinical examination followed by radiological, serological and operative findings were recorded. Data was analyse to study the male: female ratio, etiologies of viscous injury, investigation done and possible management for the treatment. Results: On analysis of the data, most common reason for the abdominal trauma was found to be road traffic accident followed by stab injury. The maximum of the patients belong to the age group of 2 to 30 years. Most common reason for the abdominal trauma was found to be road traffic accident followed by stab injury. Conclusion: It is mostly seen in the age group of 21-30 years which form the young and reproductive group. These patients' measures should be taken to prevent these accidents and care of victims at the accident site. Well established trauma care centers should be established at least at every taluk hospital. Measures for early transport of the patients from the accident site to the trauma care centres to be undertaken.

Keywords: Viscus Perforation, Roadside traffic, symptoms, abdominal pain

Corresponding Author: Pranjal Sangole, Assistant Professor, Department of Surgery, Gujarat Adani Institute of Medical Science, Bhuj, Gujarat, India.

E-mail: drpranjalsangole@gmail.com

Received: 9 January 2020

Revised: 12 February 2020

Accepted: 20 February 2020

Published: 26 May 2020

\section{Introduction}

Blunt abdominal trauma results in injury to the bowel and mesenteries in 3-5\% of cases. The injuries are polymorphic including hematoma, seromuscular tear, perforation, and ischemia. They preferentially involve the small bowel and may result in bleeding and/or peritonitis. An urgent laparotomy is necessary if there is evidence of active bleeding or peritonitis at the initial examination, but these situations are uncommon. ${ }^{[1,2]}$

Hollow viscus injuries in Abdominal trauma refers to injuries pertaining to GI tract from cardiac end of oesophagus to anus, gall bladder and biliary tract and lower genito-urinary tract. In 1990, approximately 5 million people died worldwide as a result of injury. The risk of death from injury varied strongly by religion,age, and sex. Approximately 2 male deaths due to violence were reported for every female death. Injuries accounted for approximately $12.5 \%$ of all male deaths, compared with $7.4 \%$ of female deaths. ${ }^{[3,4]}$
The diagnosis of hollow viscus injury with advanced diagnostic tools and management of trauma by conservative and surgically by laparotomy and correction of anatomy. Hence such injuries are frequently overlooked leading to increased morbidity and mortality. ${ }^{[5]}$ Thus, this study is intended to throw light upon the prompt diagnosis and management of hollow viscus injuries in trauma. Hence the aim of the present research was to study the diagnosis and management of hollow viscus injuries.

\section{Subjects and Methods}

The present research was conducted on the patient admitted in the surgical department of the medical college for the period of three years. The patients with the gastrointestinal perforation and along with history of stab injuries, mechanical crush injuries were included in the study. A total of 100 cases were included in the study. All the patients were above the age of 11 years and maximum age of 80 years. Most of the patient 
included were male with ration of $4: 1$.

The ethical clearance certificate was obtained from the college ethical committee. Most of the patients admitted in the hospital were from rural area. Patients with age less than age of 11 years, presence of genitourinary, biliary and pancreatic injury and the person with injuries caused by blast injuries were excluded from the study.

Data collection was done through history collection. After recording of history clinical examination followed by radiological, serological and operative findings were recorded. Data was analyse to study the male: female ratio, etiologies of viscous injury, investigation done and possible management for the treatment. All 51 bowel perforations were treated with 2 layered closures, with only 3 patients requiring resection and anastamosis. Omental and mesenteric injuries were treated by simple suturing and ligating the bleeding points A total of nine patients died in the present study.

\section{Results}

The age range of the included patients was from 11 years to 80 years. The maximum of the patients belong to the age group of 2 to 30 years that was followed by $11-20$ years. Out of the total 100 patients majority of them were males that account for $84 \%$ as compared to $16 \%$ of females [Table 1].

On analysis of the data, most common reason for the abdominal trauma was found to be road traffic accident followed by stab injury. Maximum of 64 cases were recorded with etiology of road traffic accident followed by 30 cases of stab injury. [Table 2] On analysis of the symptoms present: abdominal pain, distention, hematuria, pallor, vomiting and absent bowel sound were found in the patients. Abdominal pain was the most common symptom present found in all the cases, followed by presence abdominal distension in 54 cases and followed by vomiting found in 44 cases. [Table 3]

\begin{tabular}{|c|c|}
\hline Age groups & No. of patients \\
\hline $11-20$ & 28 \\
\hline $21-30$ & 32 \\
\hline $31-40$ & 24 \\
\hline $41-50$ & 12 \\
\hline $51-60$ & 2 \\
\hline $61-70$ & 1 \\
\hline $71-80$ & 1 \\
\hline
\end{tabular}

\begin{tabular}{ll}
\hline \multicolumn{2}{|c|}{ Table 2: Mode of injury of abdominal trauma } \\
\hline Causative agent & No. of cases \\
\hline Road traffic accident & 64 \\
\hline Stab injury & 30 \\
\hline Fall from height & 4 \\
Bull gore & 1 \\
Crush injury & 1 \\
\hline
\end{tabular}

\begin{tabular}{|c|c|}
\hline Sign and symptoms & 100 \\
\hline Abdominal pain & 44 \\
\hline Vomiting & 54 \\
\hline Abdominal distension & 12 \\
\hline Hematuria & 52 \\
\hline Rigidity & 42 \\
\hline Pallor & 30 \\
\hline Free fluid & 80 \\
\hline
\end{tabular}

\section{Discussion}

Hollow viscus injuries (HVIs) are uncommon and found in $1 \%$ of all blunt abdominal trauma patients. Due to their rarity, experience with this injury is limited and no strong consensus exists in the literature regarding diagnosis and management of bowel injuries. ${ }^{[6,7]}$ In penetrating trauma, early abdominal exploration is mandatory in $80 \%$ of cases and HVI diagnosis is prompt and easy. In blunt trauma, the non-operative management of solid organ injury has clearly increased the risk of delayed diagnosis and treatment of bowel lesions. ${ }^{[8,9]}$

In the present study majority of patients belonged to 21-30 years of age group, followed by 11-20 years age group. In Franklin et al, ${ }^{[5]}$ study the majority of patients belonged to 21-30 years age group. Therefore it can be concluded that the young and the productive age group people are the usual victims of abdominal trauma. road traffic accidents are the first common mode of injury. This is due to the rapid development in technology, in all fields including automobile industry where the first priority has been given to speed rather than safety.

\section{Conclusion}

It is mostly seen in the age group of 21-30 years which form the young and reproductive group. These patients measures should be taken to prevent these accidents and care of victims at the accident site. Well established trauma care centres should be established at least at every taluka hospital. Measures for early 
transport of the patients from the accident site to the trauma care centres to be undertaken.

\section{References}

1. Bège $\mathrm{T}$, Brunet $\mathrm{C}$, Berdah SV. Hollow viscus injury due to blunt trauma: A review. J Vis Surg. 2016;153(4):61-68. Available from: https://dx.doi.org/10.1016/j.jviscsurg.2016.04. 007. doi:10.1016/j.jviscsurg.2016.04.007.

2. LeBedis CA, Anderson SW, Soto JA. CT Imaging of Blunt Traumatic Bowel and Mesenteric Injuries. Radiologic Clin North Am. 2012;50(1):123-136. Available from: https://dx.doi.org/10. 1016/j.rcl.2011.08.003. doi:10.1016/j.rcl.2011.08.003.

3. A E, KJ S, E P, CJ B, K Y, KA F. Surveillance for violent deaths - National Violent Death Reporting System, 32 States, 2016. MMWR Surveill Summ. 2019;68:1-36.

4. Pruitt B, Wolf SE, Mason A. Epidemiological, demographic, and outcome characteristics of burn injury. Total burn care. 2012;4:15-45.

5. Franklin GA, Casós SR. Current advances in the surgical approach to abdominal trauma. Injury. 2006;37(12):1143-1156. Available from: https://dx.doi.org/10.1016/j.injury.2006.07.018. doi:10.1016/j.injury.2006.07.018.

6. Allen GS, Moore FA, Cox CS, Wilson JT, Cohn JM, Duke JH. Hollow Visceral Injury and Blunt Trauma. J Trauma. 1998;45(1):69-77. Available from: https://dx.doi.org/ 10.1097/00005373-199807000-00014. doi:10.1097/00005373199807000-00014.
7. Mingoli A, Torre ML, Brachini G, Costa G, Balducci G, Frezza $\mathrm{B}$, et al. Hollow viscus injuries: predictors of outcome and role of diagnostic delay. Ther Clin Risk Manag . 2017; Volume 13:1069-1076. Available from: https://dx.doi.org/10.2147/tcrm. s136125. doi:10.2147/tcrm.s136125.

8. Barnett RE, Love KM, Sepulveda EA, Cheadle WG. Article Commentary: Small Bowel Trauma: Current Approach to Diagnosis and Management. Am Surg. 2014;80(12):11831191. Available from: https://dx.doi.org/10.1177/ 000313481408001217. doi:10.1177/000313481408001217.

9. Eckert KL. Penetrating and Blunt Abdominal Trauma. Crit Care Nurs Q. 2005;28(1):41-59. Available from: https://dx.doi.org/ 10.1097/00002727-200501000-00005. doi:10.1097/00002727200501000-00005.

Copyright: (C) the author(s), 2020. It is an open-access article distributed under the terms of the Creative Commons Attribution License (CC BY 4.0), which permits authors to retain ownership of the copyright for their content, and allow anyone to download, reuse, reprint, modify, distribute and/or copy the content as long as the original authors and source are cited.

How to cite this article: Santoki NR, Sangole P, Rao G. Evaluation of the Viscus injury in Abdominal Trauma. Acad. J Surg. 2020;3(1):56-58.

DOI: dx.doi.org/10.47008/ajs/2020.3.1.12

Source of Support: Nil, Conflict of Interest: None declared. 